\title{
Risk factors associated with the surgical management of craniopharyngiomas in pediatric patients: analysis of 1961 patients from a national registry database
}

\author{
Joshua Bakhsheshian, MD, ${ }^{1}$ Diana L. Jin, BA, ${ }^{2}$ Ki-Eun Chang, MD, ${ }^{1}$ Ben A. Strickland, MD, ${ }^{1}$ \\ Dan A. Donoho, MD, ${ }^{1}$ Steven Cen, PhD, ${ }^{3,4}$ William J. Mack, MD, ${ }^{1}$ Frank Attenello, MD, ${ }^{1}$ \\ Eisha A. Christian, MD, ${ }^{1}$ and Gabriel Zada, MD ${ }^{1}$
}

${ }^{1}$ Department of Neurological Surgery; ${ }^{2}$ Keck School of Medicine; ${ }^{3}$ Department of Neurology; and ${ }^{4}$ Department of Radiology, Keck School of Medicine, University of Southern California, Los Angeles, California

OBJECTIVE Patient demographic characteristics, hospital volume, and admission status have been shown to impact surgical outcomes of sellar region tumors in adults; however, the data available following the resection of craniopharyngiomas in the pediatric population remain limited. The authors sought to identify potential risk factors associated with outcomes following surgical management of pediatric craniopharyngiomas.

METHODS The Nationwide Inpatient Sample database and Kids' Inpatient Database were analyzed to include admissions for pediatric patients ( $\leq 18$ years) who underwent a transcranial or transsphenoidal craniotomy for resection of a craniopharyngioma. Patient-level factors, including age, race, comorbidities, and insurance type, as well as hospital factors were collected. Outcomes analyzed included mortality rate, endocrine and nonendocrine complications, hospital charges, and length of stay. A multivariate model controlling for variables analyzed was constructed to examine significant independent risk factors.

RESULTS Between 2000 and 2011, 1961 pediatric patients were identified who underwent a transcranial $(71.2 \%)$ or a transsphenoidal (28.8\%) craniotomy for resection of a craniopharyngioma. A major predilection for age was observed with the selection of a transcranial $(23.4 \%$ in < 7-year-olds, $28.1 \%$ in 7 - to 12 -year-olds, and $19.7 \%$ in 13 - to 18 -year-olds) versus transphenoidal (2.9\% in < 7-year-olds, $7.4 \%$ in 7 - to 12 -year-olds, and $18.4 \%$ in 13 - to 18 -year-olds) approach. No significant outcomes were associated with a particular surgical approach, except that 7- to 12-year-old patients had a higher risk of nonendocrine complications (relative risk [RR] 2.42, 95\% Cl 1.04-5.65, $p=0.04$ ) with the transsphenoidal approach when compared with 13 - to 18 -year-old patients. The overall inpatient mortality rate was $0.5 \%$ and the most common postoperative complication was diabetes insipidus (64.2\%). There were no independent factors associated with inpatient mortality rates and no significant differences in outcomes among groups based on sex and race. The average length of stay was 11.8 days, and the mean hospital charge was $\$ 116,522$. Hospitals with medium and large bed capacity were protective against nonendocrine complications (RR 0.53, 95\% Cl 0.3-0.93, $p=0.03$ [medium]; RR 0.45, 95\% $\mathrm{Cl} 0.25-0.8, \mathrm{p}<0.01$ [large]) and total complications (RR 0.73, 95\% Cl 0.55-0.97, p = 0.03 [medium]; $\mathrm{RR} 0.68,95 \% \mathrm{Cl}$ $0.51-0.9, p<0.01$ [large]) when compared with hospitals with small bed capacity (<200 beds). Patients admitted to rural hospitals had an increased risk for nonendocrine complications ( $R R 2.56,95 \% \mathrm{Cl} 1.11-5.9, p=0.03$ ). The presence of one or more medical comorbidities increased the risk of higher total complications (RR 1.38, 95\% Cl 1.14-1.68), $p<0.01$ [1 comorbidity]; RR 2.37, 95\% Cl 1.98-2.84, p < 0.01 [ $\geq 2$ comorbidities]) and higher total hospital charges (RR 2.9, 95\% Cl 1.08-7.81, $p=0.04$ [1 comorbidity]; RR 9.1, 95\% Cl 3.74-22.12, $p<0.01$ [ 22 comorbidities]).

CONCLUSIONS This analysis identified patient age, comorbidities, insurance type, hospital bed capacity, and rural or nonteaching hospital status as independent risk factors for postoperative complications and/or increased hospital charges in pediatric patients with craniopharyngioma. Transsphenoidal surgery in younger patients with craniopharyngioma was a risk factor for nonendocrine complications.

https://thejns.org/doi/abs/10.3171/2016.8.FOCUS16268

KEY WORDS National (Nationwide) Inpatient Sample; Kids' Inpatient Database; craniopharyngioma; transsphenoidal; parasellar; sellar; oncology

ABBREVIATIONS DI = diabetes insipidus; HCUP = Healthcare Cost and Utilization Project; ICD-9-CM = International Classification of Diseases, Ninth Revision; Clinical Modification; KID = Kids' Inpatient Database; LOS = length of stay; NIS = Nationwide Inpatient Sample; RR = relative risk.

SUBMITTED June 28, 2016. ACCEPTED August 31, 2016.

INCLUDE WHEN CITING DOI: 10.3171/2016.8.FOCUS16268. 
$\mathrm{C}$ RANIOPHARYNGIOMAS are benign intracranial tumors derived from residual cell rests of embryonal tissue, and they have an incidence of 0.5-2.0 cases per million people. ${ }^{3,11}$ It is estimated that $30 \%-50 \%$ of craniopharyngiomas arise in pediatric patients, and although these tumors are considered benign, they can adversely impact a child's physical and psychosocial functioning. ${ }^{16,16,17}$ Surgical intervention is frequently the first step in management for tissue diagnosis and tumor debulking. ${ }^{11}$ However, given their proximity to critical structures of the brain such as the hypothalamus, complete resection is often difficult and postoperative complications include new neurological deficits, endocrine dysfunction, and visual deterioration. ${ }^{11,21,23,28,30}$ Additionally, increased morbidity rates associated with surgical treatment may have long-standing physical and social effects on patients, and can contribute to increased total cost of health care..$^{14,25,26,29}$ Therefore, it is important to identify preoperative risk factors associated with poor surgical outcomes in pediatric patients with craniopharyngiomas.

Previous national database registry studies investigating the resection of sellar region tumors have shown that patient demographic characteristics, hospital volume, or hospital admission subtypes are associated with postoperative endocrine and nonendocrine complications, mortality rates, or hospital charges. ${ }^{2,26,29}$ Recently, the Nationwide Inpatient Sample (NIS) was analyzed for adult patients undergoing surgery for craniopharyngiomas. ${ }^{29}$ The authors reported that hospitals with a low procedural volume had greater postoperative complications and inpatient charges. The analysis was limited to the adult population, and factors associated with surgical outcomes in pediatric patients remain unclear. Therefore, we sought to investigate the impact of demographic characteristics, hospital type, and route of admission on postoperative complications and hospital charges in children undergoing surgical treatment for craniopharyngiomas.

\section{Methods \\ Database}

This study used 2 public all-payer inpatient care datasets from the Healthcare Cost and Utilization Project (HCUP). The NIS (https://www.hcup-us.ahrq.gov/ nisoverview.jsp) and Kids' Inpatient Database (KID) (https://www.hcup-us.ahrq.gov/kidoverview.jsp) have longitudinal hospital inpatient discharge data from more than 1000 hospitals. The NIS entailed $20 \%$ of all hospital discharges and the KID contained $80 \%$ of pediatric discharges. Data from the KID was available for the years 2000, 2003, 2006, and 2009. For the years that the KID did not cover, pediatric data were extracted from the 2000-2011 NIS database. The NIS also has a built-in method for obtaining national estimates of prevalence, as described by the HCUP-NIS.?

\section{Criteria for Inclusion and Exclusion}

The study population was limited to children $(\leq 18$ years) with craniopharyngiomas who underwent a transsphenoidal or transcranial craniotomy. Admission data were extracted using the International Classification of
Diseases, Ninth Revision; Clinical Modification (ICD-9$\mathrm{CM}$ ) codes. ${ }^{1}$ The criteria for inclusion/exclusion were similar to the previous published adult report unless otherwise noted.$^{29}$ Patients with an ICD-9 code of 237.0 (craniopharyngioma) who underwent a transsphenoidal or transcranial procedure $(07.61,07.62,07.64,07.65)$ were included. Patients $>18$ years and those with a concomitant diagnosis code of 253.8 (other disorders of the pituitary and other syndromes of diencephalohypophyseal origin, excluding a diagnosis of craniopharyngioma) were excluded from the study.

\section{Risk Factors}

Patient variables including race, payer status, sex, admission source (emergency room, another hospital, other health facility, including long-term facilities, court/law enforcement, routine), and admission type (emergency, urgent, elective, trauma center, newborn) were encoded as categorical variables in NIS. Factors that were continuous were recoded into new categorical variables, such as number of comorbidities $(0,1$, or $\geq 2$ comorbidities) and age ( $<7,7-12$, or $13-18$ years). Hospital capacity was coded as small ( $<200$ beds); medium (201-400 beds); or large ( $>400$ beds). Other categorical hospital variables included teaching status, children's hospital type, and hospital region. Additionally, each hospital's annual transsphenoidal and transcranial procedural volume was calculated and categorized, and individual hospitals were categorized as low volume ( $\leq 80$ th percentile for annual procedures) or high volume ( $>80$ th percentile for annual procedures).

\section{Outcomes of Interest}

An emphasis was placed on hospital complications that occurred during admission. We examined endocrine complications (panhypopituitarism: 253.7, diabetes insipidus [DI]: 253.50, electrolyte abnormalities: 276.00-276.52, 276.61-276.90); nonendocrine complications (CSF rhinorrhea: 349.81, postoperative neurological complications: 997.00-997.09, intracerebral hemorrhage or hematoma: 430.00-432.90, 998.11-998.13, 374.31, 378.50-378.56, cranial nerve palsy: $368.20,374.30$, cerebral arteriogram: 884.10, mechanical ventilation: 967.0-967.2, blood transfusion: 990.40 , deep venous thrombosis/pulmonary embolism: 415.00, 415.11-415.19, 453.81-453.89, inferior vena cava filter installation: 387.00 ); or any complication (either endocrine or nonendocrine).

\section{Statistical Analysis}

Outcomes of endocrine complications, nonendocrine complications, total complications, and mortality rates were assessed for significance with socioeconomic, patient, hospital, and admission variables. Other outcomes of interest included specific endocrine complications, length of stay (LOS), and total charges. The LOS was considered increased if it was more than 7 days, and total charges were considered high if they were at or above the 90th percentile (\$217,985.08, adjusted for inflation). Patient factors included the following: race, insurance type, comorbidity, sex, and age. Hospital factors included region, teaching status, children's hospital type, bed capacity, and proce- 
dure volume. Last, admission variables included admission source and admission type.

The survey weight-adjusted procedure (SAS surveymean) was used for descriptive statistics. A multivariate Poisson regression using the Generalized Linear Mixed Model (SAS glimmix) with a log link function was used to examine the association (rate ratio) between risk factors and outcome. A 5-step approach was used as the modelbuilding strategy (Table 1). Akaike's Information Criterion (AIC) and Bayesian Information Criterion (BIC) were used to monitor the improvement of modeling fitting after adding an additional set of covariates. Changes of beta coefficients were also monitored to inspect the impact of an existing association after adding more covariates. Given that Model 4 controlled for the most confounding variables, only the findings from this model were presented as the final result. Statistical significance was set at $p<0.05$ for all analyses. All analyses were performed using SAS version 9.4 .

\section{Results \\ Patient Characteristics}

Between 2000 and 2011, 1961 pediatric patients were identified who underwent a transcranial $(71.2 \%)$ or transsphenoidal (28.8\%) craniotomy for resection of a craniopharyngioma. There was no gender predilection. Most of the patients were older (13-18 years old, 38.1\%), white $(43 \%)$, privately insured $(60.4 \%)$, and had no comorbidity $(45 \%)$ (Table 2). The majority of procedures took place in a teaching institution (94.7\%), with large capacity (65.1\%), and more likely to be located in the South (43.1\%) (Table $3)$. Most of the admissions were considered elective (52\%). The most common complication recorded was DI (64.2\%) (Table 4$)$ and the mortality rate was $0.5 \%(n=9)$. The average LOS was 11.8 days and the mean hospital charge was $\$ 116,522$. The surgical approach in each age group is shown in Table 5.

\section{Patient Demographic Variables}

There were no significant differences among sex and race for all measured outcomes. There were no significant factors associated with the surgical approach (transcranial vs transphenoidal; $p>0.05$ ), except that 7- to 12-year-old patients had a higher risk of nonendocrine complications

\section{TABLE 1. The 5-step model used to perform statistical analysis}

\begin{tabular}{cc}
\hline Step & \multicolumn{1}{c}{ Description } \\
\hline 1 & $\begin{array}{c}\text { A univariate model was created to validate variables for multi- } \\
\text { variable regressions analysis }\end{array}$ \\
\hline 2 & $\begin{array}{c}\text { Model } 1 \text { was created to adjust for patient-level factors (race, } \\
\text { insurance status, age category, no. of comorbid conditions, } \\
\text { \& sex) }\end{array}$ \\
\hline 3 & $\begin{array}{c}\text { Model 2 added hospital variables (bed size, region, teaching } \\
\text { status, location, children's specialty status, procedure vol) to }\end{array}$ \\
\hline 4 & Model 1 \\
\hline 5 & Model 3 added the variable admission type to Model 2 \\
\hline
\end{tabular}

TABLE 2. Cohort demographic variables-patient factors in 1961 patients with craniopharyngioma

\begin{tabular}{|c|c|}
\hline Variable \& Category & Percentage \\
\hline \multicolumn{2}{|l|}{ Sex } \\
\hline Male & 50.3 \\
\hline Female & 47.2 \\
\hline Missing & 2.5 \\
\hline \multicolumn{2}{|l|}{ Age } \\
\hline$<7$ yrs old & 26.3 \\
\hline $7-12$ yrs old & 35.6 \\
\hline $13-18$ yrs old & 38.1 \\
\hline \multicolumn{2}{|l|}{ Race } \\
\hline White & 43.0 \\
\hline Black & 8.7 \\
\hline Hispanic & 18.8 \\
\hline Asian/Pacific & 2.1 \\
\hline Native American & 1.2 \\
\hline Other & 5.8 \\
\hline Missing & 20.4 \\
\hline \multicolumn{2}{|l|}{ Payer status } \\
\hline Medicare & NA \\
\hline Medicaid & 33.0 \\
\hline Private/HMO & 60.4 \\
\hline Self-pay & 2.6 \\
\hline No charge & NA \\
\hline Other & 3.5 \\
\hline Missing & NA \\
\hline \multicolumn{2}{|l|}{ Comorbidity } \\
\hline No comorbidity & 45.0 \\
\hline 1 comorbidity & 28.1 \\
\hline$\geq 2$ comorbidities & 26.9 \\
\hline
\end{tabular}

$\mathrm{HMO}=$ health maintenance organization; $\mathrm{NA}=$ not available.

The risk of individual identification of persons is increased when the number of observations in any given cell is $\leq 10$.

(relative risk [RR] 2.42, 95\% CI 1.04-5.65, $\mathrm{p}=0.04$ ) with the transphenoidal approach when compared with 13- to 18 -year-old patients. Compared with patients $13-18$ years old, 7- to 12-year-olds were more likely to have higher total hospital charges (RR 3.44, 95\% CI 1.55-7.64, p < 0.01 ), and patients $<7$ years old were more likely to have a longer hospital stay (RR 1.5, 95\% CI 1.11-2.02, p < 0.01).

The presence of one or more comorbidities (Table 6) increased the risk of endocrine-related complications (RR $1.38,95 \%$ CI 1.1-1.72, $\mathrm{p}<0.01$ [1 comorbidity]; RR 2.18, 95\% CI 1.77-2.69, $\mathrm{p}<0.01$ [ $\geq 2$ comorbidities]); electrolyte abnormality (RR 2.15, 95\% CI 1.12-4.1, $\mathrm{p}=0.02$ [1 comorbidity]; RR 9.2, 95\% CI 5.29-15.99, $\mathrm{p}<0.01[\geq 2$ comorbidities]); higher total complications (RR 1.38, 95\% CI 1.14-1.68, $\mathrm{p}<0.01$ [1 comorbidity]; RR 2.37, 95\% CI $1.98-2.84, \mathrm{p}<0.01$ [ $\geq 2$ comorbidities]); and accrued higher hospital charges (RR 2.95, 95\% CI 1.08-7.81, p $=0.04$ [ 1 comorbidity]; RR 9.16, 95\% CI 3.74-22.12, $\mathrm{p}<$ 0.01 [ $\geq 2$ comorbidities]) compared with patients with no comorbidities (Tables 7 and 8). Two or more comorbidities 
TABLE 3. Patient demographic variables-hospital factors in 1961 patients with craniopharyngioma

\begin{tabular}{|c|c|}
\hline Variable \& Category & Percentage \\
\hline \multicolumn{2}{|l|}{ Hospital region } \\
\hline Northeast & 18.2 \\
\hline Midwest & 15.8 \\
\hline South & 43.1 \\
\hline West & 22.9 \\
\hline \multicolumn{2}{|l|}{ Teaching status } \\
\hline Nonteaching & 3.3 \\
\hline Teaching & 94.7 \\
\hline Missing & 2.0 \\
\hline \multicolumn{2}{|l|}{ Hospital capacity } \\
\hline Small & 10.9 \\
\hline Medium & 22.1 \\
\hline Large & 65.1 \\
\hline Missing & 2.0 \\
\hline \multicolumn{2}{|l|}{ Hospital location } \\
\hline Rural & 2.3 \\
\hline Urban & 95.7 \\
\hline Missing & 2.0 \\
\hline \multicolumn{2}{|l|}{ Hospital type } \\
\hline Not children's & 6.8 \\
\hline Children's general & 12.8 \\
\hline Children's unit & 16.0 \\
\hline Missing & 64.4 \\
\hline \multicolumn{2}{|l|}{ Hospital vol } \\
\hline$<2$ ops annually & 50.0 \\
\hline$\geq 2$ ops annually & 50.0 \\
\hline \multicolumn{2}{|l|}{ Admission type } \\
\hline Emergency & 19.4 \\
\hline Urgent & 13.1 \\
\hline Elective & 52.0 \\
\hline Newborn & NA \\
\hline Trauma center & NA \\
\hline Missing & 15.4 \\
\hline \multicolumn{2}{|l|}{ Admission source } \\
\hline ER & 10.1 \\
\hline Another hospital & 2.4 \\
\hline Other facility & 1.2 \\
\hline Routine & 58.5 \\
\hline Missing & 27.5 \\
\hline
\end{tabular}

$\mathrm{ER}=$ emergency room.

placed the patients at higher risk for DI (RR $1.54,95 \%$ CI $1.2-1.97, \mathrm{p}<0.01)$ and nonendocrine complications (RR $3.11,95 \%$ CI 2.15-4.49, $\mathrm{p}<0.01)$. Medicaid patients were more likely to have postoperative panhypopituitarism than patients with private insurance (RR 2.28, 95\% CI 1.14$4.56, \mathrm{p}=0.02$ ).

\section{Hospital Factors and Admission Status}

Hospitals with medium (201-400) and large (> 400)
TABLE 4. Outcomes in 1961 patients with craniopharyngioma

\begin{tabular}{lcc}
\hline \multicolumn{1}{c}{ Event } & Percentage & $95 \% \mathrm{Cl}$ \\
\hline DI & 64.2 & $59.1-69.2$ \\
\hline Electrolyte abnormality & 19.7 & $15.7-23.8$ \\
\hline RBC transfusion & 8.1 & $5.2-11$ \\
\hline Neurological complications & 7.3 & $4.8-9.7$ \\
\hline Panhypopit & 6.8 & $4.6-8.9$ \\
\hline Cranial nerve palsy & 6.3 & $3.5-9.2$ \\
\hline Mechanical ventilation & 5.9 & $3.6-8.3$ \\
\hline Any ICH & 2.7 & $1.3-4.1$ \\
\hline CSF rhinorrhea & 0.9 & $0.2-1.7$ \\
\hline Cerebral arteriogram & 0.6 & $0-1.3$ \\
\hline IVC filter & 0.5 & $0-1.2$ \\
\hline Pneumonia & 0.4 & $0-0.9$ \\
\hline DVT/PE & 0.3 & $0-0.7$ \\
\hline
\end{tabular}

DVT/PE = deep venous thrombosis/pulmonary embolism; ICH = intracerebral hemorrhage or hematoma; IVC = inferior vena cava; panhypopit = panhypopituitarism; RBC $=$ red blood cell.

bed capacity were protective against nonendocrine complications (RR 0.53, 95\% CI 0.3-0.93, $\mathrm{p}=0.03$ [medium]; RR $0.45,95 \%$ CI $0.25-0.8, \mathrm{p}<0.01$ [large]) and total complications (RR 0.73, 95\% CI 0.55-0.97), $\mathrm{p}=0.03$ [medium]; RR 0.68, 95\% CI 0.51-0.9, p < 0.01 [large]) when compared with hospitals with small bed capacity $(<200$ beds) (Table 9). Centers with high ( $\geq 2$ procedures annually) and low ( $<2$ procedures annually) procedural volume had similar outcomes.

Compared with admissions in urban hospitals, patients admitted to rural hospitals had an increased risk for nonendocrine complications (RR 2.56, 95\% CI 1.11-5.9, $\mathrm{p}=$ $0.03)$. Teaching hospitals were less likely to have postoperative panhypopituitarism (RR $0.27,95 \%$ CI $0.09-0.83$, p $=0.02)$, had lower daily hospital charges (RR $0.3,95 \% \mathrm{CI}$ $0.11-0.82, p=0.02$ ) but similar total charges when compared with nonteaching hospitals (Tables 9 and 10).

Using the Northeast region as the reference point, none of the regions of hospital location were at increased risk for postoperative complications or hospital costs. The South and Midwest had lower rates of postoperative panhypopituitarism (RR 0.33, 95\% CI 0.15-0.75, p < 0.01; RR $0.21,95 \%$ CI $0.06-0.77, \mathrm{p}=0.02$ ). Admission source and type were not significant for most outcomes assessed (Tables 11 and 12), except that admission from the emergency room was associated with a longer hospital stay (RR 1.58, 95\% CI 1.13-2.19, $\mathrm{p}<0.01)$.

TABLE 5. Surgical approach in each age group in 1961 patients with craniopharyngioma

\begin{tabular}{ccc}
\hline Patient Age & \% Transsphenoidal & \% Transcranial \\
\hline$<7$ yrs & 2.9 & 23.4 \\
\hline $7-12$ yrs & 7.4 & 28.1 \\
\hline $13-18$ yrs & 18.4 & 19.7 \\
\hline Total & 28.8 & 71.2 \\
\hline
\end{tabular}




\section{Discussion}

The surgical management of craniopharyngiomas is complex and can present unique challenges in the pediatric population. ${ }^{5,11,21,28,30}$ By analyzing the NIS and KID national databases, we identified the clinical outcomes and key risk factors for complications in children undergoing surgical management of craniopharyngiomas. The average LOS (11.8 days vs 7.6 days), postoperative DI (64.2\% vs $48 \%$ ), and hospital charge ( $\$ 116,522$ vs $\$ 92,300$ ) were greater in children compared with adults. ${ }^{29}$ According to our analysis, the mortality rate was still low $(0.5 \%)$. We identified age, comorbidities, insurance type, hospital bed capacity, and rural or nonteaching hospital status as independent risk factors associated with postoperative complications and/or increased hospital charges.

\section{Patient Demographic Variables}

Outcomes between the transphenoidal and transcranial approach were similar, except that younger patients were found to have a higher risk of nonendocrine complications with the transphenoidal approach. These complications included any postoperative neurological complications $(17.5 \%)$, cranial nerve palsy (4.6\%), mechanical ventilation (3.0\%), need for postoperative cerebral arteriogram (1.1\%), intracerebral hemorrhage or hematoma $(0.9 \%)$, and blood transfusion $(0.9 \%)$. The transphenoidal approach was more commonly used in children $>12$ years old. Transsphenoidal pituitary surgery is generally associated with a shorter LOS, lower cost, and lower complication rates than transcranial surgery. ${ }^{24}$ The risk for neurological complications from the endonasal approach could be due to age-related anatomical differences found at the skull base. A quantitative radio-anatomical cross-sectional study of pediatric patients found that the maximum sellar floor thickness decreased with age in pediatric patients. ${ }^{22}$ The varied sellar floor thickness, with a more limited surgical corridor in younger children, may place the 7- to 12-year-olds at great-

TABLE 6. Frequency and percentage of comorbidity in patient cohort in 1961 patients with craniopharyngioma

\begin{tabular}{|c|c|c|c|c|c|c|c|c|c|}
\hline \multirow[b]{3}{*}{ Comorbidity } & \multicolumn{4}{|c|}{ Surgical Patients } & \multicolumn{4}{|c|}{ Nonsurgical Patients } & \multirow{3}{*}{$\begin{array}{l}\text { All Patients } \\
\text { Freq }\end{array}$} \\
\hline & \multicolumn{2}{|c|}{ KID } & \multicolumn{2}{|c|}{ NIS } & \multicolumn{2}{|c|}{ KID } & \multicolumn{2}{|c|}{ NIS } & \\
\hline & Freq & $\%$ & Freq & $\%$ & Freq & $\%$ & Freq & $\%$ & \\
\hline Other neurological disorders & 143 & 8.4 & 313 & 18.3 & 255 & 7.8 & 550 & 16.7 & 1260 \\
\hline Hypothyroidism & 118 & 6.9 & 364 & 21.3 & 192 & 5.9 & 375 & 11.4 & 1050 \\
\hline Fluid \& electrolyte disorders & 98 & 5.8 & 246 & 14.4 & 196 & 6.0 & 368 & 11.2 & 907 \\
\hline Obesity & 41 & 2.4 & 76 & 4.5 & 83 & 2.5 & 191 & 5.8 & 391 \\
\hline Paralysis & 16 & 0.9 & 60 & 3.5 & 53 & 1.6 & 157 & 4.8 & 286 \\
\hline Chronic pulmonary disease & 39 & 2.3 & 73 & 4.3 & 67 & 2.1 & 94 & 2.9 & 274 \\
\hline Anemia (deficiency) & 32 & 1.9 & NA & NA & 37 & 1.1 & 63 & 1.9 & 131 \\
\hline Depression & NA & NA & NA & NA & 26 & 0.8 & 57 & 1.7 & 83 \\
\hline DM (uncomplicated) & NA & NA & NA & NA & 25 & 0.8 & 52 & 1.6 & 77 \\
\hline Hypertension & 21 & 1.2 & NA & NA & 26 & 0.8 & NA & NA & 46 \\
\hline Coagulopathy & NA & NA & NA & NA & 25 & 0.8 & NA & NA & 25 \\
\hline AIDS & NA & NA & NA & NA & NA & NA & NA & NA & NA \\
\hline Alcohol abuse & NA & NA & NA & NA & NA & NA & NA & NA & NA \\
\hline RA/collagen vascular disease & NA & NA & NA & NA & NA & NA & NA & NA & NA \\
\hline Anemia (chronic blood loss) & NA & NA & NA & NA & NA & NA & NA & NA & NA \\
\hline Congestive heart failure & NA & NA & NA & NA & NA & NA & NA & NA & NA \\
\hline DM w/ chronic complication & NA & NA & NA & NA & NA & NA & NA & NA & NA \\
\hline Drug abuse & NA & NA & NA & NA & NA & NA & NA & NA & NA \\
\hline Liver disease & NA & NA & NA & NA & NA & NA & NA & NA & NA \\
\hline Lymphoma & NA & NA & NA & NA & NA & NA & NA & NA & NA \\
\hline Metastatic cancer & NA & NA & NA & NA & NA & NA & NA & NA & NA \\
\hline Peripheral vascular disease & NA & NA & NA & NA & NA & NA & NA & NA & NA \\
\hline Psychosis & NA & NA & NA & NA & NA & NA & NA & NA & NA \\
\hline Pulmonary circulation disorder & NA & NA & NA & NA & NA & NA & NA & NA & NA \\
\hline Renal failure & NA & NA & NA & NA & NA & NA & NA & NA & NA \\
\hline Solid tumor w/o metastasis & NA & NA & NA & NA & NA & NA & NA & NA & NA \\
\hline Peptic ulcer disease w/o bleeding & NA & NA & NA & NA & NA & NA & NA & NA & NA \\
\hline Valvular disease & NA & NA & NA & NA & NA & NA & NA & NA & NA \\
\hline Weight loss & NA & NA & NA & NA & NA & NA & NA & NA & NA \\
\hline
\end{tabular}

$\mathrm{DM}=$ diabetes mellitus; Freq = frequency; RA = rheumatoid arthritis. 


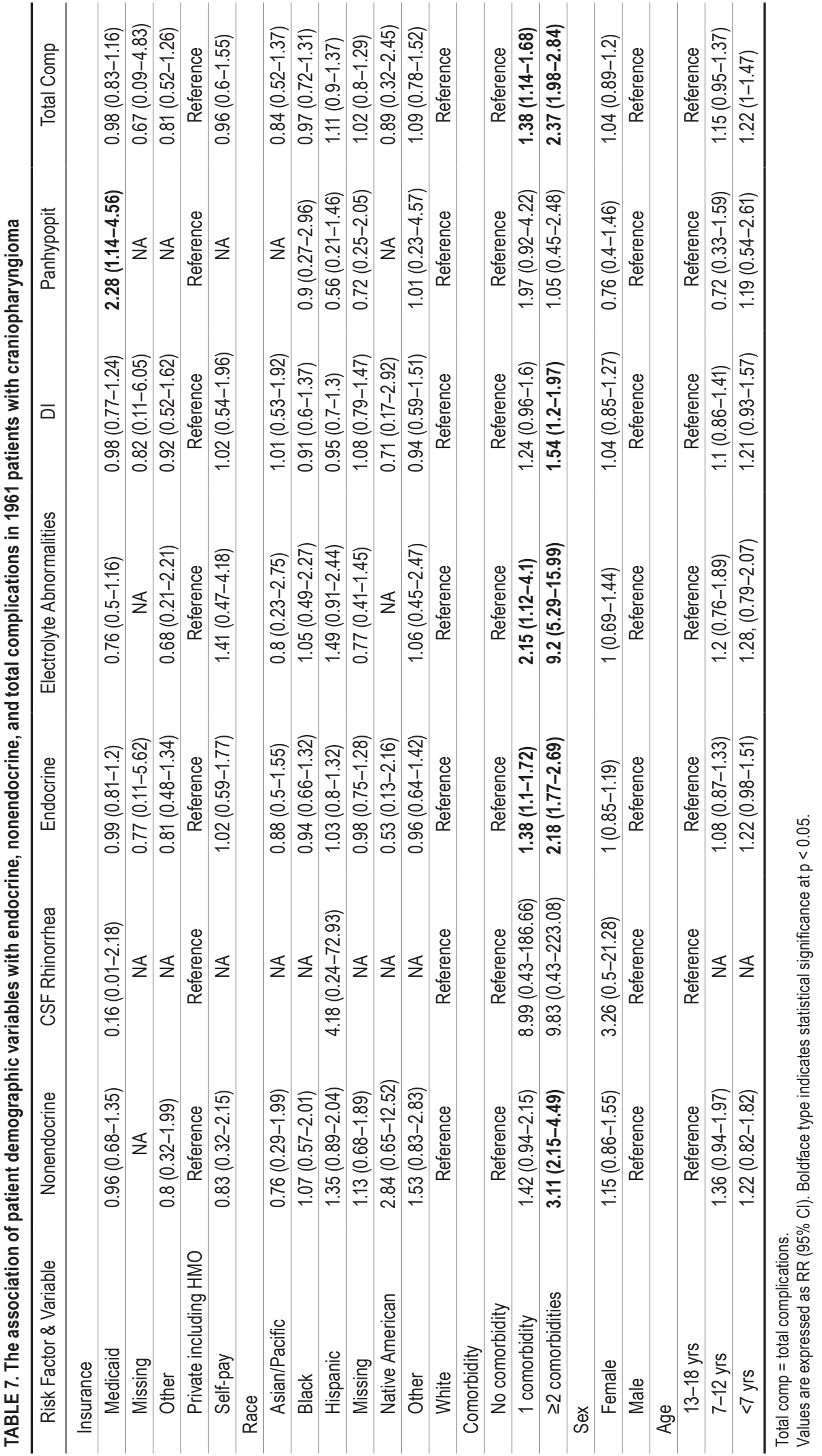


TABLE 8. The association of patient demographic variables with routine discharge, LOS, and hospital charges in 1961 patients with craniopharyngioma

\begin{tabular}{|c|c|c|c|c|}
\hline Risk Factor \& Variable & Routine & LOS & High Total Charge & High Daily Charge \\
\hline \multicolumn{5}{|l|}{ Insurance } \\
\hline Medicaid & $1.01(0.83-1.23)$ & $1.09(0.85-1.41)$ & $1.57(0.87-2.85)$ & $0.73(0.38-1.41)$ \\
\hline Missing & $0.94(0.23-3.91)$ & $0.88(0.12-6.54)$ & NA & NA \\
\hline Other & $1.05(0.68-1.62)$ & $0.74(0.37-1.46)$ & $1.37(0.3-6.21)$ & $1.41(0.41-4.85)$ \\
\hline Private including $\mathrm{HMO}$ & Reference & Reference & Reference & Reference \\
\hline Self-pay & $1.01(0.58-1.78)$ & $0.98(0.46-2.07)$ & $2.51(0.51-12.45)$ & NA \\
\hline \multicolumn{5}{|l|}{ Race } \\
\hline Asian/Pacific & $1.04(0.62-1.76)$ & $1.18(0.6-2.35)$ & $0.89(0.23-3.4)$ & $0.58(0.13-2.62)$ \\
\hline Black & $0.85(0.6-1.19)$ & $1.11(0.73-1.69)$ & $0.89(0.23-3.34)$ & $0.44(0.1-1.97)$ \\
\hline Hispanic & $0.87(0.67-1.13)$ & $1.16(0.84-1.61)$ & $1.51(0.75-3.07)$ & $0.75(0.35-1.58)$ \\
\hline Missing & $0.92(0.71-1.2)$ & $1.16(0.82-1.66)$ & $1.21(0.44-3.35)$ & $0.47(0.15-1.48)$ \\
\hline Native American & $1.08(0.44-2.68)$ & $0.47(0.06-3.46)$ & NA & $2.19(0.37-12.95)$ \\
\hline Other & $0.97(0.65-1.44)$ & $1.09(0.67-1.78)$ & $0.77(0.26-2.28)$ & $0.75(0.22-2.61)$ \\
\hline White & Reference & Reference & Reference & Reference \\
\hline \multicolumn{5}{|l|}{ Comorbidity } \\
\hline No comorbidity & Reference & Reference & Reference & Reference \\
\hline 1 comorbidity & $0.95(0.78-1.16)$ & $1.24(0.93-1.65)$ & $2.9(1.08-7.81)$ & $0.92(0.48-1.75)$ \\
\hline$\geq 2$ comorbidities & $0.83(0.67-1.04)$ & $1.57(1.2-2.06)$ & $9.1(3.74-22.12)$ & $0.92(0.46-1.81)$ \\
\hline \multicolumn{5}{|l|}{ Sex } \\
\hline Female & $0.99(0.84-1.18)$ & $1.06(0.85-1.33)$ & $1.49(0.87-2.55)$ & $0.71(0.4-1.25)$ \\
\hline Male & Reference & Reference & Reference & Reference \\
\hline Missing & $1.12(0.58-2.18)$ & NA & NA & $1.89(0.39-9.16)$ \\
\hline \multicolumn{5}{|l|}{ Age } \\
\hline $13-18$ yrs & Reference & Reference & Reference & Reference \\
\hline $7-12$ yrs & $0.98(0.8-1.21)$ & $1.33(0.99-1.77)$ & $3.44(1.55-7.64)$ & $0.83(0.43-1.58)$ \\
\hline$<7$ yrs & $1.03(0.82-1.28)$ & $1.5(1.11-2.02)$ & $2.36(1-5.57)$ & $0.89(0.45-1.79)$ \\
\hline
\end{tabular}

Values are expressed as RR $(95 \% \mathrm{Cl})$.

Boldface type indicates statistical significance at $p<0.05$.

er risk for postoperative complications. Seven- to 12-yearolds were 3.4 times more likely to have higher total hospital costs than 13- to 18-year-olds. This may be attributed to both the higher percentage of 7- to 12-year-old children undergoing a transcranial approach (Table 5) and greater risk for complications with the transsphenoidal approach.

Pediatric patients with preoperative comorbidities had significantly higher risks for nonendocrine and endocrine complications (including DI, electrolyte abnormalities, total complications, and higher total hospital charges). Because approximately $55 \%$ of the patients included in this study were found to have 1 or more comorbidity, their inherent risk for postoperative complications probably influenced the overall outcome in our study, and contributes to the nationwide trend in adverse clinical outcomes and increased health care costs. Whereas the management of comorbidities prior to surgical intervention is advocated to improve postoperative outcomes in patients undergoing intracranial tumor resections, ${ }^{10,27,29}$ surgical management of craniopharyngiomas in pediatric patients may be more complex. Unlike comorbidities in the adult population, which include cardiac, pulmonary, or renal disease, pediatric patients with craniopharyngioma generally do not have other medical issues beyond neurological or endocrine deficiencies attributed to the tumor (Table 6). The vast majority of comorbidities found in our patient cohort were probably related to the extent of tumor invasion and complexity of the resection, thereby correlating with higher risk factors.

Disparities among patients with Medicaid continue to prevail. ${ }^{15,26}$ In our analysis, we found that approximately $6.8 \%(\mathrm{n}=133)$ of patients had postoperative panhypopituitarism, and that patients with Medicaid were 2.35 times more likely to have this complication than were patients with private insurance. Previous univariate analysis conducted for patients with Cushing's disease undergoing transsphenoidal craniotomy demonstrated an association between panhypopituitarism and Medicare enrollment. However, the significance was lost when controlled for admission type and source. ${ }^{26}$ Given the limitation of the study design, we were unable to assess whether patients with Medicaid and at higher risk for complications were confounded by the extent of tumor involvement, resection, or other factors that could impact outcomes. Nonetheless, increased awareness of this ongoing disparity in the Medicaid population is still warranted. 


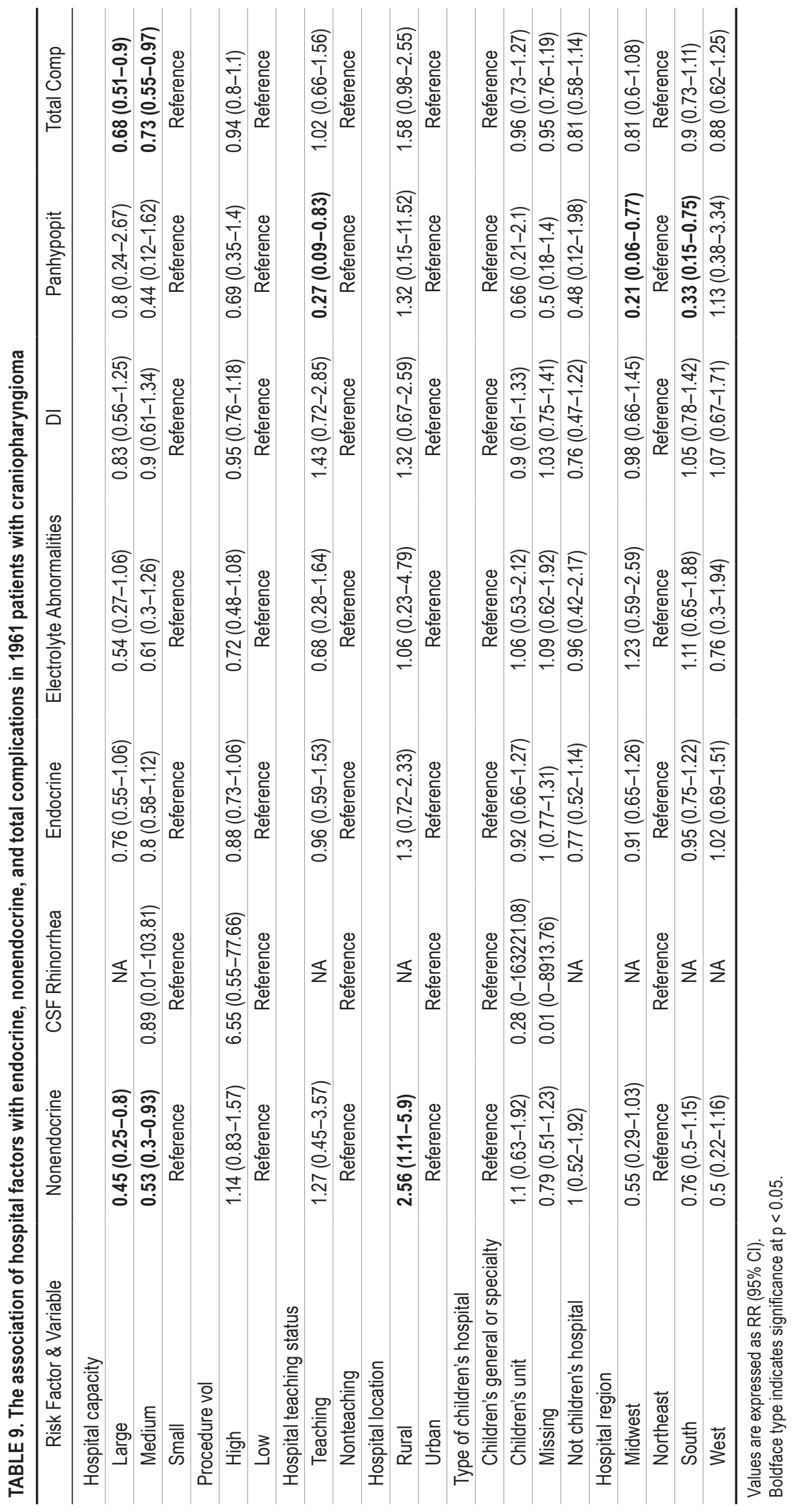


TABLE 10. The association of hospital factors with routine discharge, LOS, and hospital charges in 1961 patients with craniopharyngioma

\begin{tabular}{|c|c|c|c|c|}
\hline Risk Factor \& Variable & Routine & LOS & High Total Charge & High Daily Charge \\
\hline \multicolumn{5}{|l|}{ Hospital capacity } \\
\hline Large & $1.02(0.72-1.43)$ & $0.93(0.58-1.47)$ & $0.61(0.17-2.21)$ & $3.53(0.7-17.75)$ \\
\hline Medium & $1.04(0.74-1.46)$ & $0.97(0.62-1.52)$ & $1.38(0.4-4.73)$ & $1.07(0.21-5.51)$ \\
\hline Small & Reference & Reference & Reference & Reference \\
\hline \multicolumn{5}{|l|}{ Procedure vol } \\
\hline High & $0.97(0.81-1.16)$ & $0.95(0.75-1.22)$ & $0.83(0.46-1.48)$ & $0.96(0.52-1.75)$ \\
\hline Low & Reference & Reference & Reference & Reference \\
\hline \multicolumn{5}{|l|}{ Hospital teaching status } \\
\hline Teaching & $1.08(0.67-1.75)$ & $1.29(0.65-2.59)$ & $0.37(0.1-1.4)$ & $0.3(0.11-0.82)$ \\
\hline Nonteaching & Reference & Reference & Reference & Reference \\
\hline \multicolumn{5}{|l|}{ Hospital location } \\
\hline Rural & $0.92(0.48-1.77)$ & $1.39(0.66-2.94)$ & $1.04(0.13-8.31)$ & NA \\
\hline Urban & Reference & Reference & Reference & Reference \\
\hline \multicolumn{5}{|l|}{ Type of children's hospital } \\
\hline Children's general or specialty & Reference & Reference & Reference & Reference \\
\hline Children's unit & $0.96(0.69-1.34)$ & $1.03(0.66-1.59)$ & $1.96(0.74-5.16)$ & $0.47(0.16-1.44)$ \\
\hline Missing & $1.01(0.77-1.32)$ & $1.06(0.74-1.52)$ & $1.04(0.48-2.25)$ & $0.65(0.25-1.71)$ \\
\hline Not children's hospital & $0.9(0.62-1.31)$ & $1.19(0.73-1.96)$ & $0.65(0.17-2.54)$ & $0.34(0.1-1.15)$ \\
\hline \multicolumn{5}{|l|}{ Hospital region } \\
\hline Midwest & $1.26(0.91-1.74)$ & $0.87(0.56-1.34)$ & $0.38(0.1-1.47)$ & $1.6(0.47-5.44)$ \\
\hline Northeast & Reference & Reference & Reference & Reference \\
\hline South & $1.23(0.95-1.6)$ & $0.96(0.7-1.33)$ & $0.6(0.28-1.26)$ & $1.14(0.4-3.24)$ \\
\hline West & $1.22(0.82-1.81)$ & $1(0.59-1.7)$ & $0.46(0.13-1.63)$ & $2.51(0.79-8.04)$ \\
\hline
\end{tabular}

Values are expressed as RR $(95 \% \mathrm{Cl})$.

Boldface type indicates statistical significance at $p<0.05$.

\section{Hospital Factors}

Higher hospital volume and specific surgical caseloads have previously been associated with improved healthrelated outcomes. ${ }^{2,6,20,29} \mathrm{We}$ found no difference in complication rates and hospital charges between centers with high and low procedural volume in our patient cohort. Zaidi et al. found that patients at high-volume centers had fewer complications than patients at low-volume hospitals when assessing surgical risk factors in adult patients with craniopharyngiomas. It is possible that the finding by Zaidi et al. may have been attributed to an unmeasured confounding variable. These authors also used a dichotomized classification system, in which hospitals were classified as either low-volume $(\leq 20$ procedures over a 5 -year period) or high-volume ( $>20$ procedures over a 5 -year period) centers. In our analysis, the mean annual procedural volume was 1.5 ; therefore we dichotomized low-volume centers (those with $<2$ procedures annually; $\leq 80$ th percentile for annual procedures), or high-volume centers (those with $\geq 2$ procedures annually; $>80$ th percentile for annual procedures), which we acknowledge as a limitation of the current study. The referral pattern to high-volume hospitals can also include more complicated cases, ${ }^{19}$ thereby masking any protective effects. There could also be a threshold at which there are insufficient resources for the volume of procedures, thereby compromising the protective impact of higher-volume centers. This is in line with the finding that hospitals with greater bed capacity were protective for total complications and nonendocrine complications when compared with hospitals with lower bed capacity (Table 8).

Differences in complication rates can also be attributed to the availability of pediatric neurosurgeons with experience in skull base surgery. Multiple studies have shown a marked difference in outcome according to the neurosurgeons' experience with craniopharyngiomas. ${ }^{13,18,21} \mathrm{We}$ were unable to determine the number and level of experience of surgeons managing the patients with craniopharyngiomas. However, a small percentage of patients were treated at rural $(2.3 \%)$ or nonteaching (3.3\%) hospitals, which were associated with an increased risk for nonendocrine complications and panhypopituitarism, respectively. Patients treated at a children's hospital showed no difference in our analysis; however, the large number with missing data (64\%) may limit the relevance of this finding. A large percentage of data were also missing for admission source $(27.5 \%)$ and admission type (15.4\%), which may limit interpretation of their associations. In agreement with Zaidi et al., we believe that a prospective study is needed to assess the outcomes after referring complex lesions of the sellar region to highly specialized tertiary centers. 

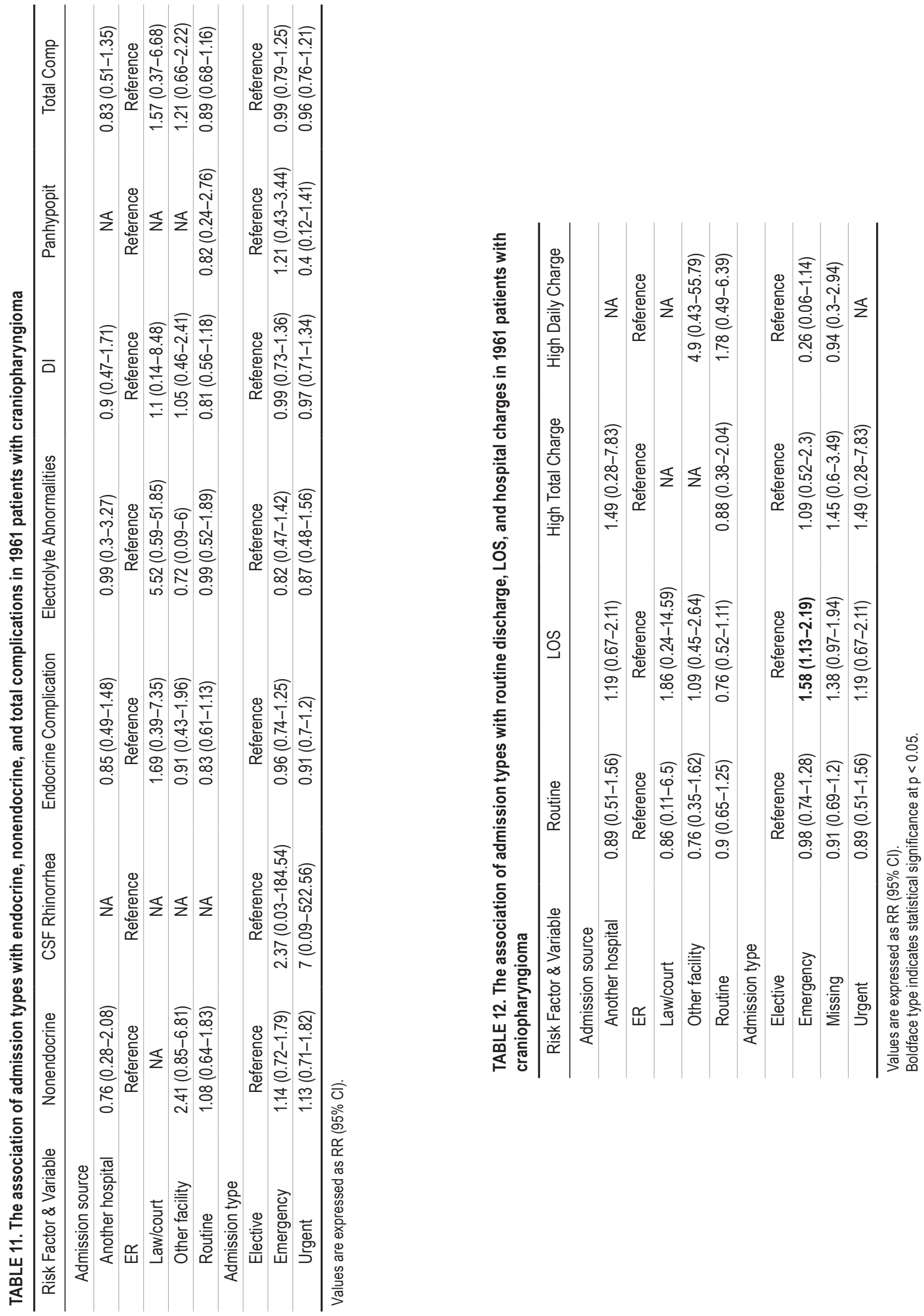


\section{Limitations and Strengths}

The use of a large population-based administrative database carries many limitations. The existence of coding error has previously been shown, ${ }^{4,8}$ and this can have an impact on the coding of diagnoses, covariates, and complications. The database is limited to inpatient records for a single admission, and does not capture complications that occur on subsequent admissions. Therefore, we were unable to distinguish between transient and permanent DI. A large limitation of this study is that the database does not contain specific information about the tumor (size, location, invasion, and so on), which has previously been shown to have a strong impact on patient outcomes. The costs analyzed were mainly due to hospital charges, and did not include professional fees and noncovered charges.

The main strength of this study is the use of a national database to analyze a large number of patients during an 11-year period, while incorporating a multivariate model to deduce multiple confounding factors. The associations do not imply direct causes, but rather the need for prospective trials to further identify the impact of these highlighted factors. The development of national databases has made it possible to accrue enough data to investigate clinical questions that would otherwise be difficult to answer. Although these databases carry many limitations, they still provide a great deal of clinical information acquired from assessing a large pool of patients with similar conditions. We used 2 large national databases, the NIS and the KID, to evaluate risk factors associated with the surgical management of craniopharyngiomas in pediatric patients. The KID is the largest publicly available pediatric inpatient care database in the US, and it was developed through a federal, state, and industry partnership sponsored by the Agency for Healthcare Research and Quality. In future studies, other prospective databases, such as the Pfizer International Growth Database (KIGS) of patients treated with growth hormone, can be included to further investigate the impact of growth hormone treatment and the presence of obesity in patients undergoing surgery for craniopharyngioma.?

\section{Conclusions}

This analysis identified age, comorbidities, insurance type, hospital bed capacity, and rural or nonteaching hospitals as independent risk factors for postoperative complications and/or hospital costs in pediatric patients who underwent surgery for craniopharyngioma. Further clinical studies are warranted to investigate the impact of these variables on complications and hospital costs.

\section{References}

1. American Medical Association: ICD-9-CM: International Classification of Diseases, 9th Revision, Clinical Modification. Volumes 1 and 2. Chicago: American Medical Association, 2006

2. Barker FG II, Klibanski A, Swearingen B: Transsphenoidal surgery for pituitary tumors in the United States, 1996-2000: mortality, morbidity, and the effects of hospital and surgeon volume. J Clin Endocrinol Metab 88:4709-4719, 2003

3. Bunin GR, Surawicz TS, Witman PA, Preston-Martin S, Davis F, Bruner JM: The descriptive epidemiology of craniopharyngioma. J Neurosurg 89:547-551, 1998
4. Burns EM, Rigby E, Mamidanna R, Bottle A, Aylin P, Ziprin $\mathrm{P}$, et al: Systematic review of discharge coding accuracy. J Public Health (Oxf) 34:138-148, 2012

5. Cohen M, Bartels U, Branson H, Kulkarni AV, Hamilton J: Trends in treatment and outcomes of pediatric craniopharyngioma, 1975-2011. Neuro Oncol 15:767-774, 2013

6. Cowan JA Jr, Dimick JB, Leveque JC, Thompson BG, Upchurch GR Jr, Hoff JT: The impact of provider volume on mortality after intracranial tumor resection. Neurosurgery 52:48-54, 2003

7. Geffner M, Lundberg M, Koltowska-Häggström M, Abs R, Verhelst J, Erfurth EM, et al: Changes in height, weight, and body mass index in children with craniopharyngioma after three years of growth hormone therapy: analysis of KIGS (Pfizer International Growth Database). J Clin Endocrinol Metab 89:5435-5440, 2004

8. Gologorsky Y, Knightly JJ, Lu Y, Chi JH, Groff MW: Improving discharge data fidelity for use in large administrative databases. Neurosurg Focus 36(6):E2, 2014

9. Houchens R, Elixhauser A: Final Report on Calculating Nationwide Inpatient Sample (NIS) Variances, 2001. Rockville, MD: Agency for Healthcare Research and Quality, 2005

10. McGirt MJ, Chaichana KL, Gathinji M, Attenello F, Than K, Ruiz AJ, et al: Persistent outpatient hyperglycemia is independently associated with decreased survival after primary resection of malignant brain astrocytomas. Neurosurgery 63:286-291, 2008

11. Müller HL: Consequences of craniopharyngioma surgery in children. J Clin Endocrinol Metab 96:1981-1991, 2011

12. Özyurt J, Müller HL, Thiel CM: A systematic review of cognitive performance in patients with childhood craniopharyngioma. J Neurooncol 125:9-21, 2015

13. Puget S, Garnett M, Wray A, Grill J, Habrand JL, Bodaert N, et al: Pediatric craniopharyngiomas: classification and treatment according to the degree of hypothalamic involvement. $\mathbf{J}$ Neurosurg 106 (1 Suppl):3-12, 2007

14. Rolston JD, Han SJ, Lau CY, Berger MS, Parsa AT: Frequency and predictors of complications in neurological surgery: national trends from 2006 to 2011. J Neurosurg 120:736745,2014

15. Rosenberg AR, Kroon L, Chen L, Li CI, Jones B: Insurance status and risk of cancer mortality among adolescents and young adults. Cancer 121:1279-1286, 2015

16. Rosenfeld A, Arrington D, Miller J, Olson M, Gieseking A, Etzl M, et al: A review of childhood and adolescent craniopharyngiomas with particular attention to hypothalamic obesity. Pediatr Neurol 50:4-10, 2014

17. Sands SA, Milner JS, Goldberg J, Mukhi V, Moliterno JA, Maxfield C, et al: Quality of life and behavioral follow-up study of pediatric survivors of craniopharyngioma. J Neurosurg 103 (4 Suppl):302-311, 2005

18. Sanford RA: Craniopharyngioma: results of survey of the American Society of Pediatric Neurosurgery. Pediatr Neurosurg 21 (Suppl 1):39-43, 1994

19. Sharma M, Sonig A, Ambekar S, Nanda A: Discharge dispositions, complications, and costs of hospitalization in spinal cord tumor surgery: analysis of data from the United States Nationwide Inpatient Sample, 2003-2010. J Neurosurg Spine 20:125-141, 2014

20. Smith ER, Butler WE, Barker FG II: Craniotomy for resection of pediatric brain tumors in the United States, 1988 to 2000: effects of provider caseloads and progressive centralization and specialization of care. Neurosurgery 54:553565,2004

21. Sughrue ME, Yang I, Kane AJ, Fang S, Clark AJ, Aranda D, et al: Endocrinologic, neurologic, and visual morbidity after treatment for craniopharyngioma. J Neurooncol 101:463476, 2011 
22. Tatreau JR, Patel MR, Shah RN, McKinney KA, Wheless SA, Senior BA, et al: Anatomical considerations for endoscopic endonasal skull base surgery in pediatric patients. Laryngoscope 120:1730-1737, 2010

23. Unsinn C, Neidert MC, Burkhardt JK, Holzmann D, Grotzer M, Bozinov O: Sellar and parasellar lesions-clinical outcome in 61 children. Clin Neurol Neurosurg 123:102-108, 2014

24. Villwock JA, Villwock MR, Goyal P, Deshaies EM: Current trends in surgical approach and outcomes following pituitary tumor resection. Laryngoscope 125:1307-1312, 2015

25. Visser J, Hukin J, Sargent M, Steinbok P, Goddard K, Fryer $\mathrm{C}$ : Late mortality in pediatric patients with craniopharyngioma. J Neurooncol 100:105-111, 2010

26. Wilson D, Jin DL, Wen T, Carmichael JD, Cen S, Mack WJ, et al: Demographic factors, outcomes, and patient access to transsphenoidal surgery for Cushing's disease: analysis of the Nationwide Inpatient Sample from 2002 to 2010. Neurosurg Focus 38(2):E2, 2015

27. Woodworth GF, Chaichana KL, McGirt MJ, Sciubba DM, Jallo GI, Gokaslan Z, et al: Predictors of ambulatory function after surgical resection of intramedullary spinal cord tumors. Neurosurgery 61:99-106, 2007

28. Zada G, Laws ER: Surgical management of craniopharyngiomas in the pediatric population. Horm Res Paediatr 74:62-66, 2010

29. Zaidi HA, Chapple K, Little AS: National treatment trends, complications, and predictors of in-hospital charges for the surgical management of craniopharyngiomas in adults from 2007 to 2011. Neurosurg Focus 37(5):E6, 2014

30. Zygourakis CC, Kaur G, Kunwar S, McDermott MW, Madden M, Oh T, et al: Modern treatment of 84 newly diagnosed craniopharyngiomas. J Clin Neurosci 21:1558-1566, 2014

\section{Disclosures}

The authors report no conflict of interest concerning the materials or methods used in this study or the findings specified in this paper.

\section{Author Contributions}

Conception and design: Zada, Bakhsheshian, Jin. Acquisition of data: Bakhsheshian, Jin. Analysis and interpretation of data: Zada, Bakhsheshian, Jin, Chang. Drafting the article: Bakhsheshian, Jin. Critically revising the article: Zada, Bakhsheshian, Chang, Strickland, Cen, Mack, Attenello, Christian. Reviewed submitted version of manuscript: all authors. Statistical analysis: Bakhsheshian, Jin, Cen. Administrative/technical/material support: Bakhsheshian, Cen. Study supervision: Zada.

\section{Correspondence}

Gabriel Zada, Department of Neurological Surgery, Keck School of Medicine, University of Southern California, 1200 North State St., Ste. 5046, Los Angeles, CA 90089. email: gzada@usc.edu. 